\title{
A comprehensive, health-promotion approach to tobacco control
}

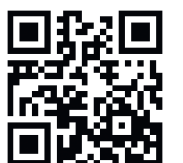

A comprehensive health promotion approach to tobacco control can work among school-age children in Africa. This is the message from the study by Reddy et al. ${ }^{[1]}$ reported in this month's SAMJ. The data sustaining the message were drawn from four Global Youth Tobacco Surveys (GYTSs) conducted among nationally representative samples of South African (SA) school learners during 1999, 2002, 2008, and 2011. The setting was public schools across the 9 provinces of SA, and the more than 7000 learners in grades 8 - 10, aged 12 - 20 years. The percentage of learners who admitted to being current smokers (smoked a cigarette on at least one day in the 30 days preceding the survey) declined from $23 \%$ in 1999 to $16.9 \%$ in 2011 - a $26.5 \%$ reduction. Reductions in smoking prevalence, however, were less pronounced among girls and among ethnic black learners.

These remarkable changes occurred during a time when smoking among young people was on the rise globally. At that time, also the SA Government, of which I was privileged to serve as Minister of Health from 1994 to 1999, was introducing a comprehensive set of health promotion measures to curb the harmful effects of tobacco use on health. ${ }^{[2-5]}$ These included interventions at the ecological level such as legislation banning the advertising of tobacco products, classifying nicotine as an addictive drug, restricting smoking in public places, and increasing excise duties on cigarettes. In addition, there were interventions aimed at the individual such as school health education and improving health literacy, and changes in the national school curriculum declaring nicotine a drug of addiction.

The GYTSs show that as well as a $26.5 \%$ decline in smoking prevalence among these adolescents over a 12 -year period, changes in smoking-related attitudes and behaviours also occurred among these learners, reflecting what were profound socio-cultural shifts in attitudes to smoking in SA society at large during those years, resulting in sustained reductions of $54 \%$ in per capita cigarette consumption among adults during the same period. ${ }^{[6]}$ Of concern, however, in the two GYTSs from 2008 to 2011, was an observed increase in smoking prevalence in learners, particularly notable in girls, who are known to be a principal target for the tobacco industry, which seeks to recruit adolescents into a lifetime of addiction to nicotine.

These findings are important, as hitherto most nationally representative data on the impact of tobacco control measured over a period of more than a decade came from high-income countries (HIC). The tobacco industry, on the other hand, has targeted lowand middle-income countries (LAMICs) such as our own, where $80 \%$ of smokers now reside, as its target for market growth in tobacco consumption over the coming years. The GYTSs demonstrate that public health measures in tobacco control, using a health promotion approach, do work, and could be adopted by countries across the developing world in the setting of the Framework Convention on Tobacco Control (FCTC) for example, ${ }^{[7]}$ and utilising WHO's 'MPOWER' strategy.

The African National Congress, which in 1994 formed the first democratic government in SA under President Nelson Mandela, first adopted a tobacco control policy in the early 1990s. This escalated into a pan-African view on tobacco control, with African countries playing leading roles in the development of the FCTC. This view considered issues such as demand reduction, as well as supply reduction, through tobacco crop substitution in African countries. African countries are continuing to mobilise around issues of tobacco control. Many have signed the FCTC and several have implemented elements of the MPOWER programme, such as research and monitoring. This is critically important as Africa's population is set to double by the middle of the 21 st century to reach 2 billion, more than half of whom will be the young people, and especially young women, that the tobacco industry seeks to recruit to smoking. African countries are monitoring tobacco use among adults, such as in Nigeria, Africa's most populous country, which showed that in 2012, 5.6\% of adults were current smokers - $10 \%$ of men, and $1.1 \%$ of women. ${ }^{[8]}$ The GYTSs show that monitoring is also possible across a decade-long timespan of tobacco use among children in Africa.

Sub-Saharan Africa is still in the early stages of the tobacco epidemic and must intervene now to prevent tobacco-related death, disease, and economic and environmental burden. Therefore, the African Union Commission, together with the US Institute of Medicine of the National Academy of Science and other partners, has formed a committee to 'inform, engage and mobilise highlevel African leadership to prioritise tobacco control to mitigate the tobacco epidemic. ${ }^{[9]}$ The main deliverable of this multilateral partnership is the production of an authoritative, evidence-informed, tobacco control policy document, jointly issued from the partnering African Science Academies, summarising the potential negative health and socioeconomic effects of tobacco on sub-Saharan Africa, as well as recommended tobacco control strategies. ${ }^{[9]}$

Africa and countries across the globe, LAMICs together with HICs, need to continually refine their strategies and methods for tobacco prevention and smoking cessation. The GYTSs represent a good foundation on which to build, in terms of monitoring tobacco use at a national level among adolescents, as well as detecting areas of concern that may inform new research and interventions.

\section{Nkosazana Dlamini Zuma}

Chairperson of the African Union

Former Minister of Health of the Republic of South Africa

1. Reddy P, James S, Sewpaul R, et al. A decade of tobacco control. The South African case of politics, health policy, health promotion and behaviour change. S Afr Med J 2013;103(11):835-840. [http:// dx.doi.org/10.7196/SAMJ.6910]

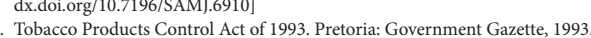

Tobacco Products Control Amendment Act No. 12 of 1999. Vol. 406. Pretoria: Government Gazette, 1999. 3. Tobacco Products Control Amendment Act No. 12 of 1999. Vol. 406. Pretoria: Government Gazette, 1999 5. Tobacco Products Control Amendment Act No. 63 of 2008. Vol. 523. Pretoria: Government Gazette, 2009. 6. van Walbeek C. Recent trends in smoking prevalence in South Africa - some evidence from AMPS data. S Afr Med J 2002;92(6):468-472.

World Health Organization. WHO Framework Convention on Tobacco Control (WHO FCTC), 2003. http://www.who.int/fctc/text_download/en/ (accessed 14 May 2013).

. GATS: Nigeria. Global Adult Tobacco Survey: Country Report, 2012. http://nccd.cdc.gov/gtssdata/ Ancillary/DataReports.aspx?CAID $=3$ (accessed 13 September 2013).

9. Institute of Medicine of the National Academies and the African Union Commission Committee. Building Leadership to Address the Negative Effects of Tobacco on Africass Health, Economy and Development. http://www.iom.edu/Activities (accessed 13 September 2013).

S Afr Med J 2013;103(11):831. DOI:10.7196/SAMJ.7305 